\title{
Role playing game: uma ferramenta pedagógica para ensinar e aprender filosofia no ensino médio
}

\section{Role playing game: a pedagogical tool to teach and learn philosophy in high school}

\author{
Andreza Dantas \\ Mestranda na Universidade Estatual do Rio Grande do Norte, Caicó, Rio Grande Norte, Brasil. \\ profandrezamagda@gmail.com - https://orcid.org/0000-0002-8861-1628
}

\section{Antunes Ferreira Silva}

Doutorando na Universidade Federal de Sergipe, Aracajú, Sergipe e professor pela Universidade Federal de Campina Grande, Campina Grande, Paraíba, Brasil.

antunnes_ferreira@hotmail.com - https://orcid.org/0000-0003-3201-1145

\author{
Antônio Garcia Freire \\ Professor doutor na Universidade do Estado do Rio Grande do Norte, Caicó, Rio Grande do Norte, \\ Brasil. \\ prof.antoniojulio@gmail.com - https://orcid.org/0000-0003-2415-6344
}

Recebido em 29 de junho de 2020

Aprovado em 02 de outubro de 2020

Publicado em 28 de outubro de 2020

\section{RESUMO}

O desafio de promover um ensino que permita o aluno a alcançar objetivos de aprendizagem está cada vez mais complexo, por isso, pensar novas práticas metodológicas, capazes de auxiliar a aprendizagem está cada vez mais complexo. Mediante dilema, refletimos uma nova prática metodológica, aliada ao uso de ferramentas tecnológicas. Nesse sentido, surgiu o questionamento: De que maneira o uso do RPG como ferramenta pedagógica auxilia o processo ativo da aprendizagem nas aulas de filosofia? E partindo desta pergunta, o presente artigo procura: a) refletir brevemente sobre a metodologia de ensino da filosofia; b) pensar as novas estratégias para o Ensino de Filosofia; c) discutir o ensino Filosofia por intermédio de jogos digitais; e, d) apresentar o RPG como ferramenta pedagógica capaz de promover a aprendizagem. Para uma melhor explanação sobre o assunto, a metodologia da pesquisa será de cunho bibliográfico, realizada a partir dos referenciais teóricos que percorrem o campo do Ensino da Filosofia (GALLO; ASPIS, 2009), revisitando os documentos oficiais que regulamentam a presença da disciplina no ensino médio (PCNS, OCNS). Os estudos dos jogos clássicos (HUIZINGA, 2007), jogos digitaisRPG (LIMA, 2012), gamificação e ludicidade (GUIMARÃES; SIGNORI, 2016) PAIVA, 2016) SILVIA, 2017). Com isso, ao final da pesquisa espera-se que a aprendizagem mediada pelos jogos desloque o aluno da posição de mero espectador para o papel de protagonista, desempenhando um papel mais ativo. Portanto, o presente artigo visa contribuir com a inovação do processo de ensino-aprendizagem do ensino de filosofia no ensino médio. Palavras-chave: Ensino de Filosofia; Aprendizagem; Role Playing Game (RPG).

\section{ABSTRACT}

The challenge of promoting teaching that allows the student to achieve learning objectives is increasingly complex, therefore, thinking about new methodological practices, capable of assisting learning is increasingly complex. 
Through a dilemma, we reflect a new methodological practice, combined with the use of technological tools. In this sense, the question arose: How does the use of RPG as a pedagogical tool help the active learning process in philosophy classes? Based on this question, this article seeks to: a) briefly reflect on the methodology of teaching philosophy; b) think about the new strategies for Teaching Philosophy; c) discuss Philosophy teaching through digital games; d) presenting RPG as a pedagogical tool capable of promoting learning. For a better explanation on the subject, the research methodology will be bibliographic in nature, based on the theoretical frameworks that cover the field of Philosophy Teaching (GALLO; ASPIS, 2009), revisiting the official documents that regulate the presence of the discipline in secondary education (PCNS, OCNS). The studies of classic games (HUIZINGA, 2001), digital games- RPG (LIMA, 2012), gamification and playfulness (GUIMARÃES, 2019; PAIVA, 2019; SILVIA, 2017) With this, at the end of the research it is expected that learning mediated by the games move the student from the position of mere spectator to the role of protagonist, playing a more active role. Therefore, this article aims to contribute to the innovation of the teaching-learning process of teaching philosophy in high school. Keywords: Philosophy teaching; Learning; Role Playing Game (RPG).

\section{Introdução}

Perante a realidade que se apresenta nas escolas, percebe-se que somente o domínio dos conteúdos, por parte do professor, das várias áreas da filosofia não são suficientes para a efetiva aprendizagem do aluno, embora tal perspectiva esteja em um contexto vital para que os objetivos de ensino-aprendizagem sejam atingidos. Desta forma, evidencia-se uma necessidade de novos aportes metodológicos e de práticas de ensino que favoreçam uma educação inovadora alinhada com as transformações tecnológicas e científicas recentes, as quais exigem novos olhares, métodos e abordagens teórico-práticas, permitindo novas configurações sociais, fundadas na ética e no respeito à diversidade.

Quando refletimos sobre a possibilidade do uso de novas práticas metodológicas capazes de auxiliar o processo de ensino e aprendizagem da filosofia, podemos observar com mais atenção a rotina dos estudantes e buscar perceber em quais atividades extra classe eles apresentam mais engajamento e de que maneira poderíamos utilizar tal engajamento como agente motivador para a aprendizagem da filosofia, e por conseguinte, contribuir com o processo de formação dos sujeitos envolvidos.

A observação do cotidiano nos mostrou como os alunos interagem entre si e como se relacionam com as Novas Tecnologias da Informação e Comunicação (NTIC) através de aplicativos de socialização, interação e entretenimento. Neste último caso, destacamos o grande interesse dos alunos pelos jogos digitais. Por este motivo, foi delineada a presente proposta, no sentido de utilizá-los como recurso metodológico aplicado ao ensino de filosofia, cuja finalidade será a construção de um instrumento didático lúdico, destinado a tornar o processo de aprendizagem agradável, divertido e produtivo. No âmbito dos tipos classificados como "jogos digitais", destacamos o jogo de interpretação de papéis ou jogo de atuação em primeira pessoa (RPG), devido a sua grande aceitação entre os jovens e seu caráter de transversalidade, influenciando e sendo influenciado por diversas manifestações culturais contemporâneas, tais como o cinema, séries de televisão e streaming, arte sequencial e a literatura fantástica. Deste modo, a realização desta pesquisa busca analisar o uso do RPG como ferramenta pedagógica no processo ativo da aprendizagem nas aulas de filosofia.

O Role Playing Game ${ }^{1}$ (RPG) trata de uma narrativa fictícia que envolve o jogador numa aventura de imaginação. A origem dos RPG's remonta aos jogos de tabuleiro e 
está relacionada, em grande parte, ao entretenimento de jovens imersos na produção e consumo de artefatos culturais contemporâneos em países centrais e de democracias liberais, mas alcançou um nível de popularidade mundial, passando a ser jogado por pessoas das mais diversas idades e culturas, inclusive em países periféricos. Talvez, por este motivo, o RPG tenha evoluído rapidamente, criando versões digitais offline e online.

Deste modo, acreditamos que o ensino de filosofia por meio de um jogo de atuação em primeira pessoa possibilita a melhoria das habilidades e competências dos alunos, por permitir ao professor inserir conteúdos didáticos em suas narrativas, e assim construir espaços virtuais de saber e partilha. Além disso, uma proposta deste tipo ao colocar o aluno como sujeito ativo do processo de aprendizagem no contexto do jogo, parte do pressuposto que o jogador seja tenha autonomia para tomar suas próprias decisões baseadas em princípios possíveis de serem ensinados pela educação filosófica, e assim colaborar na construção do conhecimento ativo, desenvolvendo e potencializando o diálogo entre as escolhas realizadas no mundo digital e a vida cotidiana do aluno.

\section{Para uma concepção metodológica do ensino da filosofia}

A existência da disciplina de filosofia no currículo do ensino médio brasileiro, sempre esteve historicamente relacionada aos momentos de maior ou menor carga reacionária incidente no cenário político vivenciado pelo país. Entre supressões e inclusões, a disciplina esteve envolta em polêmicas envolvendo a sua (in)capacidade em permitir uma maior potencialidade de desenvolvimento do pensamento crítico dos estudantes, especialmente se confrontamos o período militar pós-1964 com os dias atuais. Talvez por este motivo, a inclusão da filosofia no currículo do Ensino Médio como disciplina obrigatória, tenha causado discussões sobre as formas e possibilidades pelas quais 0 ensino deve acontecer, ou seja, a busca por uma metodologia de ensino "que promova maior participação e autonomia do educando" (FERREIRA; GARCIA, 2018, p. 580).

O ensino de filosofia não apresenta uma organização curricular homogênea entre as escolas brasileiras, e possivelmente este é um dos grandes desafios enfrentados pelos professores, gerando angústias acerca da busca de estratégias comuns de ensino capazes de produzir resultados de aprendizagem adequados. Além disso, no que diz respeito à formação, após a obrigatoriedade da presença da filosofia no ensino médio², os professores começaram a discutir a necessidade da qualificação metodológica. Conforme o $\S 1^{\circ}$ do artigo 36 da LDB n 9394/96, “(...) os conteúdos, as metodologias e as formas de avaliação serão organizadas de tal forma que, ao final do Ensino Médio, o educando demonstre: domínio dos conhecimentos de Filosofia e Sociologia necessários ao exercício da cidadania" (BRASIL, 1996).

Considerando os objetivos de aprendizagem propostas pela LDB, "faz-se necessário pensar que Filosofia aplicar, para que, e para quem, tarefa esta que vem sendo tema de pesquisas e debates em nosso país" (SANTOS, 2016, p. 7). Partindo do debate nacional acerca da metodologia do ensino de filosofia, e a falta de uma grade curricular específica no ensino médio, como citamos anteriormente, o Ministério da Educação- MEC, realizou a implementação de orientação por meio dos Parâmetros Curriculares Nacionais (PCN), 
as Orientações Curriculares para o Ensino Médio OCN, entre outros documentos oficiais ${ }^{3}$.

Nos documentos oficias brasileiros os professores encontram três propostas de abordagens a serem utilizadas na prática docente, a saber: a abordagem histórica, temática e conceitual/problemática. Destaca-se que a existência das abordagens supracitadas não exclui outras formas e métodos, assim como, a escolha por determinada abordagem não a elege como a melhor, muito menos como uma fórmula exata que garante ao professor a eficácia no processo do ensino-aprendizagem, tendo em vista que foram criadas para facilitar o ensino e cada uma tem a sua importância conforme o objetivo a que cada uma se propõe.

Segundo Salles et al (2019, p. 379):

Ainda que seja possível distinguir como esses conceitos são trabalhados na parte legal e como o são na parte específica da Filosofia dos Parâmetros, na qual a abordagem é, no mínimo, mais sofisticada e mais filosófica, a articulação desses conceitos aponta para uma proposta unificada, aposta na capacidade de superação do caráter fragmentário da cultura e do ensino escolar, mediante esforço interdisciplinar, crítico e racional.

No século $X X$, o ensino de filosofia ofertado no Brasil teve sua prática didática pautada na história da filosofia ${ }^{4}$. Durante muito tempo, essa prática docente foi consenso entre os professores e foi predominante como modelo de ensino nos cursos superiores de graduação universitária, na academia, e até mesmo no ensino médio, nas escolas públicas e privadas. Este modo de ensino acontece por meio da abordagem histórica, e "recaía sobre uma visão histórica da filosofia com a qual buscava-se oferecer um ensino totalizador do conteúdo filosófico" (TEIXEIRA et al.,2019, p. 7). No entanto, este modelo "não pode ser visto unicamente pelo viés histórico e conteudístico, mas sim como um processo avaliativo no qual os alunos possam vivenciar momentos de reflexão, de amadurecimento intelectual e de prática cidadã" (SANTOS, 2015, p, 25).

Não demorou muito tempo e os questionamentos acerca desta forma de ensino começaram a surgir. Refletia-se sobre a validade do modelo, e ainda, sobre se seria possível aos estudantes vivenciarem através dele, uma experiência filosófica concreta. Gallo e Aspis (2009, p. 51) alertam que este ensino se apresenta "[...] de forma condensada nos principais sistemas filosóficos, sem se importar em examinar em que medida eles podem ou não apresentar algum sentido para a vida dos jovens". Nesse sentido, Mendes (2008, apud SANTOS, 2015, p. 67) confirma que:

[...] adotar uma metodologia didática sem fugir dos PCNS e das proposições de seus eixos temáticos fez com que na práxis a capacidade do aluno em entender a Filosofa estivesse além da teoria, e isso se torna possível quando o professor desperta em seu aluno potencialidades intelectivas e problematiza-as através das competências e habilidades da Filosofia com um olhar voltado a realidade social, cultural e histórica do discente. 
Nesta perspectiva, a segunda abordagem trabalha com os grandes problemas da filosofia através de temas variados, permitindo "um resgate de questões antigas, que passam a ser vistas a partir de novas óticas, uma vez que os temas centrais da Filosofia durante os tempos, tais como a ética, a política, a arte, o conhecimento, [...], continuam, ainda hoje, sendo objeto de análise da Filosofia" (SANTOS; SILVA, 2018, p. 181). Esta proposta foi chamada de abordagem temática, e, conforme expõe Gallo e Aspis (2009, p. 51), "é mais adequada ao ensino da filosofia, se pretendemos um ensino ativo, que oportunize experiências de pensamento. Através de temas filosóficos, pensamos ser mais viável sensibilizar os estudantes para o pensamento" (GALLO; ASPIS, 2009, p. 51).

No entanto, a aceitação desta abordagem não ocorreu de maneira unânime. Enquanto teóricos já citados, acreditam na eficácia do ensino por meio de temas, outros, consideram que seria um risco colocar os temas como centro de ensino da filosofia. Ou seja, "seria também fácil cair na armadilha de desfilar uma série de temas filosóficos que nós, professores, consideramos absolutamente pertinentes e relevantes, mas que não despertam absolutamente nenhuma curiosidade nos alunos" (GALLO; ASPIS, 2009, p. 52).

No anseio de manter a especificidade da filosofia, o seu ensino não pode estar desassociado daquilo que ele promete ser. Gallo e Aspis (2009, p. 35) explicam que "é próprio da filosofia criar conceitos que permitam a contemplação, a reflexão e a comunicação, sem os quais elas não poderiam existir".

Assim Pereira (2018, p. 98) aponta que:

Em contraposição a estas duas abordagens citadas pelos PCN e OCN,
temos uma terceira perceptiva metodológica intitulada abordagem
problemática. A abordagem problemática do ensino da Filosofia tem
como principal objetivo organizar os conteúdos a ser trabalhados
de modo a explicitar problemas que fizeram os filósofos pensar e
produzir seus conceitos, qual era seu movimento de criação. E pode
ser uma maneira de o professor de Filosofia estimular os estudantes
a fazerem, também eles, a experiência do pensar filosófico.

Dessa maneira, a terceira abordagem rompe com a visão tradicional do ensino de filosofia, apresentando outras formas de lidar com as temáticas e a história da filosofia. Esta abordagem tem como característica fundamental a crítica, uma vez que "o ensino de Filosofia deve se pautar pela liberdade da formulação do problema, pela reflexão acerca de todas as facetas deste e pela busca de respostas, as quais cada indivíduo tem por obrigação intelectual encontrar" (SANTOS; SILVA, 2018, p.179).

Considerando os aspectos da abordagem centrada no problema (também chamada de abordagem problemática), observamos que esta possibilita a aplicabilidade das outras duas abordagens, ou seja, não se trata de estruturar o ensino unicamente por meio dos problemas, ou esquecer os temas já pensados pelos filósofos. Trata-se de dar sentido às questões trazidas pelos alunos, problematizando os temas de interesse dos mesmos, sem se desprezar a história da filosofia. 
É necessário que o professor evidencie os problemas que estão por trás dos temas e da história da filosofia, como motores do pensamento, como aquilo que fez com que os filósofos pensassem ao longo da história. É a capacidade de visualizar, de fato, os problemas que mobilizaram os filósofos e os movimentos e trajetórias de pensamentos que estes fizeram que pode produzir nos alunos a possibilidade de que eles se afetem também pelos problemas e se ponham no movimento do pensamento (GALLO; ASPIS, 2009, p. 51).

Entendemos que as três abordagens apresentadas apresentam potencialidades e fragilidades. Cabe ao professor, escolher dentre essas abordagens, aquela mais identificada com as necessidades de ensino-aprendizagem no seu contexto particular. Diante da breve análise das abordagens expostas nos documentos oficiais, e com base nas características presentes nos jogos digitais, a abordagem problemática teria o potencial de contribuir para que o estudante do ensino médio possa desenvolver uma reflexão sobre a resolução de problemas exercitando a autonomia intelectual e experienciando a atitude filosófica.

\section{Estratégias para o ensino de filosofia utilizando os jogos digitais}

Diante do quadro de dificuldades enfrentadas pelo ensino de filosofia, o qual foi marcado pela instabilidade da disciplina ao longo do tempo em que esteve submetida a avanços e retrocessos pela sua presença nos currículos escolares, os desafios para encontrar uma abordagem que potencialize o seu ensino tornam-se cada vez mais complexos. De fato, "os professores de filosofia vivem [..] uma situação bastante desafiadora. Após décadas de debate, de manifestações, de congressos acadêmicos e de lutas parlamentares [...]" (RODRIGO, 2009 , s./p). Nesse sentido, cabe ao professor buscar novas propostas didáticas, "de modo que o aprendizado de filosofia faça sentido para os jovens estudantes" (RODRIGO, 2009, s./p).

A preocupação com o desempenho do aluno é fundamental para conduzir a prática docente. Essa inquietação permite melhorar a metodologia aplicada na sala de aula, bem como, pensar no uso de uma nova "[...] ferramenta pedagógica, oferecendo um método alternativo, instigante e interativo para desperta interesse e a curiosidade, facilitando o aprendizado tanto do aluno como do professor através de atividades lúdicas participativas" (PAIVA, 2016, p.33).

Ao consideramos que as atividades lúdicas contribuem para a motivação do aluno no processo de ensino-aprendizagem ressaltamos que Vygotsky, destaca a importância da ação lúdica na formação cognitiva da imaginação humana, possibilitando o processo criativo da aprendizagem. De acordo Vygotsky (1991, p. 62 apud SILVA, 2017, p. 105).

A imaginação é um processo psicológico novo para a criança; representa uma forma especificamente humana de atividade consciente, não está presente na consciência de crianças muito pequenas e está totalmente ausente em animais. Como todas as funções da consciência, ela surge originalmente da ação. O velho adágio de que o brincar da 
criança é imaginação em ação deve ser invertido podemos dizer que a imaginação, nos adolescentes e nas crianças em idade pré-escolar, é o brinquedo sem ação. A ludicidade pode ser um caminho para ampliar ainda mais a aquisição do conhecimento dos alunos, bem como estimular a criação de novas práticas pedagógicas. Nesse sentido, Silva (2017, p. 104) afirma que

[...] combinar métodos lúdicos (por exemplo: cruzadinhas, apresentações teatrais, jogos eletrônicos e de tabuleiro relacionados ao tema, apresentação de diversas manifestações de arte, dentre muitos outros), podem agir como processos facilitadores para uma apresentação de conteúdos complexos, e proporcionar uma forma de apoio na função de ensino e aprendizagem por parte do professor, fortalecendo o uso da imaginação no processo cognitivo, exercitando assim o pensamento e botando em prática a criatividade.

Na maioria dos estudos sobre o processo de ensino-aprendizagem, o estudante sempre esteve como um mero espectador, enquanto que nas atividades lúdicas, o aluno não apenas vê ou escuta o mestre, mas também realiza as atividades em um processo interativo. Desta forma, o estudante torna-se agente principal na dinâmica da aprendizagem e o professor passa a ser um facilitador deste processo. Quando invertemos a posição tradicional do professoraluno, estamos nos referimos principalmente ao uso das abordagens atualmente conhecidas como metodologias ativas. Essas abordagens permitem ao professor, entre outros aspectos, a desafiar os seus alunos a construírem um caminho autônomo para a aprendizagem. O objetivo é estimular os estudantes a pensarem de forma reflexiva, crítica e autônoma, desenvolvendo a capacidade para a resolução de problemas cotidianos, e assim despertando-os para a vida. Para compreender melhor essa característica, Ferreira e Garcia (2018, p. 582) explicam que "para ocorrer à aprendizagem ativa, tem que haver o envolvimento e participação do aprendiz, ouvindo, falando, perguntando, discutindo, a fim de promover junto ao professor uma construção mais efetiva do conhecimento". Portanto, Ferreira e Garcia (2018, p. 583) garantem que:

Na metodologia ativa todas as etapas da aquisição do conhecimento
pelos discentes são conduzidas pelo docente. Este pode utilizar,
à medida que haja necessidade, de maior velocidade na busca por
informação e/ou ainda, maior interação com os alunos por meio das
tecnologias atuais. Tecnologia que a juventude muitas vezes domina,
mas nem sempre para a pesquisa acadêmica, fato que justifica a
presença do facilitador na condução do seu uso na busca pelo saber.

Investir nas metodologias ativas não significa descartar a presença do professor, pelo contrário, sem a mediação do mestre a construção do conhecimento não é possível. Assim, é papel da escola atender às necessidades dos estudantes, de modo que a sua prática enquanto instituição de ensino busque educar o indivíduo para a compreensão e respeito à diversidade de contextos e realidades humanas numa sociedade global e em rede, em que pese os seus diferentes níveis de desenvolvimento tecnológico, considerando que "As novas formas de comunicação e interação humana, assim como os novos conceitos de armazenamento, 
manipulação e difusão de informação e cultura, propiciados pelas tecnologias digitais, sugerem novas formas de ensino e de aprendizagem" (NOVAES; AZEVEDO, 2014, p. 56).

Para tanto, é necessário compreender o que se entende por novas tecnologias. Ferreira (2019, p. 3) explica que:

\begin{abstract}
Por novas tecnologias educacionais, também conhecidas como tecnologias digitais, compreendem-se os equipamentos, desenvolvidos gradativamente, desde a segunda metade da década de 1970 e, sobretudo, nos anos 1990. Moran (2000) esclarece que por recentes tecnologias em educação, entende-se o uso da informática, de ferramentas para a ferramenta a distância - como chats, grupos ou listas de discussão, correio eletrônico - e de outros recursos e linguagens digitais de que atualmente dispõe se e que podem colaborar, significativamente, para tornar o processo educativo mais interativo.
\end{abstract}

Um dos principais objetivos da inserção das novas tecnologias educacionais nos processos de ensino é o de promover práticas educativas que permitam uma maior interatividade na aprendizagem. Nesse sentido, as tecnologias surgem como um elemento potencializador da aquisição e desenvolvimento de competências e habilidades através do espaço educacional. Por outro lado, faz-se necessário destacar os desafios advindos dessa inserção, tendo em vista a variedade e desigualdade de recursos e da estrutura tecnológica existente entre regiões, comunidades e pessoas. Por um lado, é fundamental considerar em quais condições a prática docente ocorre, bem como refletir sobre as potencialidades e problemas advindos do uso das tecnologias quando são aplicadas ao ensino, em especial ao ensino de filosofia.

Por considerar que os efeitos positivos do uso das tecnologias no âmbito da educação superam as consequências deletérias, escolhemos o jogo digital - mais especificamente, o RPG - Role Playing Game - como uma estratégia possível para a prática didática do ensino de filosofia, tendo em vista que o componente lúdico dos jogos pode contribuir para aumentar a motivação dos estudantes no processo educativo, uma vez que os jogos podem proporcionar experiências desafiadoras de aprendizagem. "O ponto é que, após o término do ambiente e do tempo de jogo, do momento de ilusão espontânea e auto implicada, o jogador continua assimilando todo o conteúdo elaborado e processador durante a experiência de jogo" (KUSSLER, 2017, p.172).

\title{
Jogos digitais (RPG) no ensino de filosofia
}

Tradicionalmente, os jogos digitais foram usados como entretenimento de crianças, jovens e adultos. No entanto, recentemente novos estudos nessa temática revelam que os jogos podem apresentar outras funções, nesse caso, ligadas ao ensino e à aprendizagem. $A$ utilização dos jogos em sala de aula, ainda é pouco explorada, e no que se refere ao ensino de filosofia, essa aplicação fica ainda mais restrita. Para tanto, precisamos compreender de qual 
contexto se fala: "Os jogos por muito tempo ficaram de fora da esfera do que é considerado 'sério' e importante, porém a escola sempre esteve no ápice dos discursos daquilo que nos é mais caro e valioso para a construção de uma vida" (SILVA, 2017, p, 08). Assim, os jogos digitais são capazes de simular, promover e incorporar contextos lúdicos ao processo de aprendizagem, preenchendo as lacunas que deveriam ter origem nos estímulos externos.

Recentemente, o termo gamificação foi incorporado aos estudos, pesquisas e atividades que utilizam os jogos como recurso e abordagem metodológica de ensino e aprendizagem. Este conceito está interligado ao contexto educacional e apresenta algumas definições, a saber:

Uma das definições da gamificação por Deterding et al. (2011)
corresponde a utilização de elementos de jogos em contexto não
lúdico, com foco para melhorar o engajamento e a experiência do
usuário. Zichermann e Cunnigham (2011) afirmam que a gamificação
foi utilizada em programas de marketing e aplicações web com o
objetivo de concretizar clientes e usuários das plataformas, além de
motivar e engajar (GUIMARÃES; SIGNORI, 2016, p. 6).

Ainda uma prática recente, a gamificação tem seus embasamentos nas teorias já desenvolvidas acerca do papel do jogo na cultura humana, com destaque especial para o conceito de Homo Ludens laborado por Johann Huizinga. O filósofo afirma:

O jogo é fato mais antigo que a cultura, pois esta, mesmo em suas definições menos rigorosas, pressupõe sempre a sociedade humana; mas, os animais não esperaram que os homens os iniciassem na atividade lúdica. É-nos possível afirmar com segurança que a civilização humana não acrescentou característica essencial alguma à ideia geral de jogo. Os animais brincam tal como os homens. Bastará que observemos os cachorrinhos para constatar que, em suas alegres evoluções, encontram-se presentes todos os elementos essenciais do jogo humano. Convidam-se uns aos outros para brincar mediante um certo ritual de atitudes e gestos. Respeitam a regra que os proíbe morderem, ou pelo menos com violência, a orelha do próximo. Fingem ficar zangados e, o que é mais importante, eles, em tudo isto, experimentam evidentemente imenso prazer e divertimento. Essas brincadeiras dos cachorrinhos constituem apenas uma das formas mais simples de jogo entre os animais. Existem outras formas muito mais complexas, verdadeiras competições, belas representações destinadas a um público (HUIZINGA, 2007, p. 5).

De fato, consideramos que as estratégias lúdicas são capazes de favorecer a aplicação, compreensão e assimilação do conteúdo da disciplina da filosofia. Concordamos, com Silva (2017, p. 101) quando afirma: "A utilização de recursos lúdicos (jogos, dramatizações, quiz, quadrinhos etc.) na realidade do ensino de adolescentes, pode representar interessante iniciativa para demonstrar que estudar Filosofia pode ser divertido e útil". Para tanto, considerando as transformações sociais e tecnológicas previamente aqui citadas, propor atividades na disciplina de ensino de filosofia que façam o uso dos jogos digitais, nos convida a refletir e buscar respostas à seguinte pergunta: considerando o acelerado crescimento do uso dos jogos digitais na educação, quais 
seriam as principais características de um processo de gamificação ou de um jogo digital aplicado ao cotidiano escolar, especificamente ao contexto do ensino de filosofia?

A partir dessa questão, buscou-se um modelo de jogo típico de uma situação de entretenimento, mas que pudesse ser aplicado à dimensão do ensino, no qual as suas características e dinâmica de interação pudessem auxiliar a autonomia, motivação e memorização dos educandos, proporcionando um "ambiente de discussões mais livre, permitindo que alunos interpretem determinados personagens e, nesse jogo representativo, sintam-se mais à vontade para expor seus pensamentos e argumentar sobre temas filosóficos" (KUSSLER, 2017, p.164). Assim, o jogo de interpretação de personagens (ou papéis) conhecido como Role Playing Game (RPG) se apresentou com tais características.

Para compreendemos como funciona o RPG, Lima et al (2012, p. 2) nos explica que:

\begin{abstract}
O RPG pode ter como base vários temas, reais ou fictícios; o tempo de jogo varia: podem durar minutos, horas ou mesmo dias. O processo do jogo seria equivalente a de um esforço coletivo em se escrever uma história. A interpretação ocorre de forma descritiva, isto é, o jogador ao interpretar um personagem, irá descrever suas ações em primeira ou segunda pessoa. Isso porque o limite do fazer é bem maior do que o limite do falar, pois o primeiro está submetido ao mundo físico, e o segundo ao regime das ideias e à imaginação.
\end{abstract}

Nessa perceptiva, o RPG não é um jogo comum com características comuns, uma vez que o foco não é, por exemplo, o sistema de recompensas, e muito menos exibir ou validar um ganhador. ORPG tem uma estrutura narrativa, a qual possibilita ao jogador manipular, improvisar e interferir nas atitudes, decisões e ações de seus personagens. De certa maneira, o jogador pode optar por diversos fios narrativos, desde que a estrutura base dos personagens, cenários e regras sejam mantidos. Desta maneira, o RPG é um recurso que permite ao professor inserir conteúdos em suas narrativas permitindo que o aluno/jogador tomar suas próprias decisões.

Neste modelo, "o professor deverá selecionar alguns problemas filosóficos, de preferência que tenham uma significação existencial para os alunos, pois filosofamos quando sentimos os problemas na pele" (GALLO; ASPIS, 2009, p. 42). Deste modo, acredita-se que o RPG proporciona uma certa liberdade de escolha acerca dos problemas filosóficos, quando aplicado ao ensino de filosofia. Ao professor, caberia analisar a narrativa, explorar os elementos didáticos presentes no jogo, guiando os alunos através do processo de reflexão filosófica.

\title{
RPG: ferramenta que promove a aprendizagem
}

Pensar o ensino de filosofia sempre foi problemático entre os teóricos e especialistas no assunto. Tais dificuldades surgem uma vez que a primeira questão que se coloca para esta reflexão, não é quanto a sua modalidade de ensino, e sim, quanto a sua definição. A pergunta: "o que é filosofia?" apresenta-se como ponto de partida e, talvez, a resposta como ponto de chegada. "É preciso, pois que se tome uma posição na filosofia; que se evidencie de onde falamos, quando pensamos e praticamos seu ensino" (GALLO, 2012, p. 40).

Em entrevista concedida ao professor Walter Kohan, o filósofo Ferraro (2013, 
p.158), narra um pouco da sua experiencia com a docência e explica que a filosofia precisa afastar-se da necessidade de definir os conceitos, reconhecendo a necessidade de pensar em uma concepção específica de filosofia relacionada intrinsecamente com a vida que se leva, com as escolhas práticas, e aquilo que se faz. "Então, é oportuno que a filosofia deixe de ser algo fechado em si mesmo, feito apenas para um circuito interno, e que se abra à sociedade" Ferraro (apud KOHAN, 2013, p.158).

Com o passar do tempo, a busca por respostas nos conduz a pensar filosoficamente o ensino de filosofia. "A questão do método de ensino tem sido então um assunto importante. E uma premissa consolidou-se: quando alguém ensina, alguém aprende. Ou ainda: alguém só aprende quando um outro ensina" (GALLO, 2012, p. 67). Deste modo, à medida que as lacunas acerca da definição sobre o que é o ensino de filosofia vão aos poucos se preenchendo, as dificuldades e desafios acerca do modo como se aprende a disciplina vão aumentando, tendo em vista, a investigação incipiente sobre os modelos dessa aprendizagem. As pesquisas que se dizem centrar no processo de ensino-aprendizagem, na verdade, estão concentradas no ensino em sua perspectiva mais geral, deixando as reflexões sobre a aprendizagem no campo da filosofia esquecidas ou incompletas.

Por este motivo, um dos maiores desafios do professor de filosofia seria propor uma metodologia de ensino com foco no aluno, especificamente centrada na autonomia da aprendizagem. Assim, o uso do RPG associado à prática docente tem sido cada vez mais considerado como um recurso didático que permite expandir essa autonomia. Conforme, Freitas, et al (2018, p. 6), “[...] nos processos de aprendizagem envolvendo os games o sujeito tem autonomia para decidir sobre ações que o conduzirão ao aprendizado proposto, as quais são limitadas por regras do universo do jogo que criam desafios para estimular a sua participação e autonomia no processo de aprendizagem".

Partindo das características do RPG e as habilidades específicas que se espera do ensino da filosofia, é possível perceber algumas similaridades de propósito entre esses dois campos, principalmente quando o jogo favorece o desenvolvimento de "aspectos que vão além dos conteúdos estudados, como: efeito motivador, desenvolvimento de habilidades cognitivas, socialização, coordenação motora, dentre diversos outros aspectos" (FREITAS, et al 2018, p. 21). Assim, como consideramos os critérios do jogo, vale ratificar o papel da filosofia.

Ferreira e Garcia (2018, p. 578) nos colocam que:

A filosofia tem a intenção de estimular a consciência, de alimentar
uma posição questionadora ao homem sobre o que já foi definido por
doutrinas ou dogmas e que ainda podem ser analisadas para uma
melhor compreensão, é uma reflexão radical que exige o rompimento
de paradigmas para a construção de um novo conhecimento do
ser contemporâneo que se quer formar, auxiliando na tomada de
decisões mais coerentes e justas, não somente para si, mas para à
coletividade.

Objetivando apresentar uma reflexão sobre o benefício da inserção de uma abordagem recente para o ensino de filosofia salientamos que os RPGs não são jogos criados para fins 
educativos, por isso, situam-se na categoria de paradidáticos, considerando o seu uso no âmbito educacional, "tendo em vista que são jogos voltados para o entretenimento e possuem características que podem contribuir para apreensão de conceitos" (FREITAS, et al, 2018, p. 6).

Com efeito, "na interação com o game espera-se que o aluno-jogador possa aplicar os conhecimentos aprendidos em sala de aula, vivenciando virtualmente a experiência de atuar na prática em um ambiente realista" (FREITAS, et al. 2018, p.23). Aqui está implícita a convicção de que o RPG tem a capacidade de desenvolver um diálogo entre as escolhas realizadas no mundo digital e a vida cotidiana do aluno. Deste modo, a aplicação de jogos digitais no ensino de filosofia possibilita uma prática pedagógica lúdica e estimula a aprendizagem criatividade.

\section{Conclusão}

A educação básica sempre discutiu a sua prática docente e atualmente faz parte deste esforço de reflexão, repensar os seus métodos tradicionais de ensino. Além disso, reconhece a necessidade de revisitar seus paradigmas, transformando-os em propostas práticas e metodológicas que possam atender às necessidades das gerações atuais e futuras, tornando as salas de aulas prazerosas na construção do saber. São aspectos que tornam a escola particularmente o ensino de filosofia - um espaço democrático e de conhecimento para a vida.

Nessa vertente, um dos princípios que fundamentam algumas dessas propostas, é o de convidar o estudante a pensar e desenvolver sua própria experiência de pensamento, de forma lúdica, potencializandoas suas habilidades ecompetências, e tendo comoobjetivoa construção do conhecimento de forma crítica, reflexiva eativa, em vez de recebê-lo de forma passiva do professor.

Um dos grandes desafios para o professor de filosofia no ensino médio é refletir e colocar em prática uma abordagem metodológica de ensino capaz de conquistar o interesse dos jovens, bem como, tornar acessível a reflexão filosófica, sem sucumbir à banalização de técnicas e métodos, nem ao historicismo acadêmico, conduzindo os estudantes a refletir de forma autônima e crítica, mas amparada na tradição filosófica. Nesse sentido, a proposta deste estudo não é eleger um método exclusivo, correto ou mais adequado. Ao considerar a mediação dos jogos digitais - particularmente, o RPG - nos processos de ensino-aprendizagem que fazem parte das aulas de filosofia no ensino médio, a pesquisa sugere uma nova estratégia didática possível de ser aplicada por qualquer professor em qualquer série e escola.

\section{Referências}

BRASIL. Lei n 9.394, de 20 de Dezembro de 1996. Disponível em: http://www.planalto.gov. br/ccivil_03/leis/I9394.htm. Acesso em: Julho/2019.

FERREIRA, Edson Leone; GARCIA, Sônia Cardoso Moreira. Filosofia, aprendizagem ativa e tecnologia: balizadores para a aquisição do conhecimento.

Revista Valore, v. 3, n. 2, p. 576-596, 31 dez. 2018.

FREITAS, Eliton Elói Brandão; ALVES, Lynn Rosalina Gama; TORRES, Velda Gama Alves. SAFESKILL: um serious game para estudantes e profissionais de segurança do trabalho. Revista observatório. Vol. 4, n. 4, Jul-Set. 2018. 
GALLO, Silvio; ASPIS, Renata Pereira Lima. Ensinar Filosofia: um livro para professores. São Paulo: Atta Mídia Educação, 2009.

GALLO, Silvio. Metodologia do Ensino de Filosofia: uma didática para o ensino médio. Campinas: Papirus, 2012.

GUIMARÃES, J. C. F; SIGNORI1, G. G. Gamificação como método de ensino inovador. Rio de Janeiro v. 1, n. 1, p. 66-77, jul./dez. 2016.

HUIZINGA, Johan. Homo Ludens: o jogo como elemento da cultura. Tradução de João Paulo Monteiro Perspectiva: São Paulo, 2007.

KUSSLER, Leonardo Marques. Tradição e crítica da metodologia de Ensino de Filosofia: filosofar com Role-Playing Game (RPG). SEFIM. v. 3, n. 6, 2001.

KOHAN, Walter Omar. Disciplina e experiência: entrevista com Giuseppe Ferraro. In: CORNELLI, Gabriele. CARVALHO, Marcelo. (Org.) Filosofia e formação. Cuiabá: Central de Texto, 2013.

LIMA, Lucas Dorado; NOMURA, Marcio Tokuiti; BARROS, Leandro; VELASCO, Patrícia Del Nero. O RPG no Ensino de Filosofia: diálogo e imaginação. Anais do Simpósio do PIBID/UFABC, v. 01, 2012.

MAZAI, Norberto; RIBAS, Maria Alice Coelho. Trajetória do ensino de filosofia no Brasil. Disciplinarum Scientia. Série: Ciências Sociais e Humanas, Santa Maria, V.2, n.1, p.1-13, 2001.

NOVAES, José Luís Corrêa; AZEVEDO, Marcos Antônio. O. (Org). A filosofia e seu ensino: desafios emergentes. Porto Alegre. Sulina, 2014.

PAIVA, Alberto Carlos. A gamificação como ferramenta pedagógica no ensino superior. Barueri- SP, 2016.

PEREIRA, Andreza Magda da Silva Dantas. A importância do ensino de Filosofia no Ensino Médio: uma análise no Município de Paulista-PB. In: CAMPOS, Lindoaldo; BULHÕES, Fernanda; ARAÚJO, Joelson. (Orgs). Ensino de filosofia no ensino médio: desafios, práticas e perspectivas. Natal: PPGFIL, 2018.

SANTOS, Ivanaldo; SILVA, Raimundo Fábio. Ensino de filosofia, por temas, à luz da pedagogia histórico-crítica. Revista Eletrônica Científica Ensino Interdisciplinar. Mossoró, v. 4, n. 10, Fevereiro/2018.

SANTOS, Thiago Ferreira. Panorama histórico da filosofia no Brasil: da chegada dos jesuítas ao lugar da filosofia na atualidade. Seara Filosófica, N. 12, Inverno, 2016, P. 126-140.

SANTOS, Yvisson Gomes. O ensino da disciplina de filosofia no ensino médio analisado através de relatos de experiencias de alunos em uma escola publica de Maceió/AL. 2015. Dissertação (Mestrado em Educação) - Universidade Federal de AlagoasUFAL, Maceió, 2015.

SILVA, Ricardo. Estratégias lúdicas aplicadas à filosofia no ensino médio. Revista COMFILOTEC. V. 06, 2017.

TEIXEIRA, Gilson Ruy Monteiro; ALMEIDA, Jerusa da Silva Gonçalves; SILVA, Jussara Almeida Midlej. A filosofia enquanto disciplina no ensino médio: Abordagem histórica de sua ensinabilidade no secundário brasileiro. Disponível em: http://educonse.com. br/2012/eixo_05/PDF/17.pdf. Acesso em: 2019 


\section{Notas}

${ }^{1}$ Traduzido como Jogos de interpretação de papeis ou personagens.

${ }^{2}$ A inserção da filosofia no ensino médio se deu com a Reforma de Francisco Campos, ocorrida em 1931, quando o então ensino secundário passou a ter caráter de curso, com um currículo seriado e com frequência obrigatória. Porém, no começo da década de 1960, com a lei n. 4.024/61 (Lei de Diretrizes e Bases da Educação Nacional), o ensino de Filosofia não mais aparece como obrigatório, tornando-se facultativo. Em 1994, aconteceu o golpe militar, durante a vigência da ditadura militar o ensino de filosofia enfrentou inúmeras dificuldades para se efetivar, na medida em que o interesse pelo ensino profissionalizante ia se acentuado a filosofia ia desaparecendo dos currículos. Tal fato contribui para o total desaparecimento da disciplina, mais precisamente no ano de 1971, quando a mesma foi substituída por "componentes doutrinários como: Moral e cívica e Organização Social e Politica do Brasil, OSPB" (MAZAI; RIBAS, 2001, p.11). O retorno da filosofia como disciplina na educação básica brasileira ocorreu em 2008, com o projeto de lei 11.684/08 que alterou o artigo 36 da LDB 9394/96, tornando a Filosofia disciplina obrigatórias na grade curricular das escolas de ensino médio no Brasil.

${ }^{3}$ Atualmente, os documentos que norteiam a educação básica são a Lei $n^{\circ} 9.394$, que estabelece as Diretrizes e Bases da Educação Nacional (LDB), as Diretrizes Curriculares Nacionais para a Educação Básica e o Plano Nacional de Educação, aprovado pelo Congresso Nacional em 26 de junho de 2014. Outros documentos fundamentais são a Constituição da República Federativa do Brasil e o Estatuto da Criança e do Adolescente. ${ }^{5}$

${ }^{4}$ A mesma concepção está presente na visão de Marilena Chauí em seu Convite à Filosofia (1995). Nele, apesar dos conteúdos estarem distribuídos em torno de conceitos ou de abordagem disciplinar da filosofia, a pauta está atrelada ao viés histórico. Ou seja, a ensinabilidade da filosofia obedece ao princípio da história da filosofia (TEIXEIRA et al.,2019, p. 9).

${ }^{5}$ A gamificação é um conceito baseado no ato de exportar elementos estruturais existentes em jogos para aplicá-los em atividades que não são consideradas lúdicas, em especial as atividades que compõe rotinas de estudos, treinamentos e jornadas profissionais.

\section{Correspondência}

Andreza Dantas - Rua João Dantas de Assis, Escola Estadual Francisco De Sá Cavalcante,Centro, CEP: 58860-000, Paulista, Paraíba, Brasil.

\section{(c) (1) (8)(2)}

This work is licensed under a Creative Commons Attribution-NonCommercial 4.0 International (CC BY-NC 4.0) 